DOI: $\underline{\text { https://doi.org/10.24867/05AM08Pelagic }}$

\title{
ANALIZA TRANZIJENTNIH KARAKTERISTIKA BOČNE DINAMIKE VOZILA POMOĆU SOFTVERA ZA MODELIRANJE I SIMULACIJE
}

\section{ANALYSIS OF TRANSIENT CHARACTERISTICS OF LATERAL VEHICLE DYNAMICS WITH HELP OF SOFTWARE FOR MODELING AND SIMULATIONS}

\author{
Dalibor Pelagić, Fakultet tehničkih nauka, Novi Sad
}

\begin{abstract}
Oblast - MAŠINSTVO
Kratak sadržaj - U ovom radu je izvšena analiza uticajnih parametara na ponašanje motornih vozila pri naglim promjenama pravca kretanja, na primjeru izolovanih, pojednostavljenih manevara. Kao glavni alati za pomenutu analizu korišteni su softver Adams Car $i$ analitički proračun uz pomoć softvera Microsoft Excel.
\end{abstract}

Ključne reči: skretanje vozila, tranzijentni odziv, Adams Car

Abstract - This paper represents analysis of influential parameters on vehicle behavior during sharp cornering, on example of isolated and simlified maneuvers. The main tools used for this analysis are softwer Adams Car and analytic calculation with help of softwer Microsoft Excel.

Keywords: vehicle cornering, transient response, Adams Car

\section{UVOD}

Ponašanje motornih vozila pri savladavanju krivina određenih radijusa zavisi od velikog broja različitih parametara. Da bi se skretanje pravilno izvelo, sa što manje rizika za gubljenje kontrole, potrebna je precizna izrada pojedinih podsistema vozila, kao i pravilno upravljanje vozilom.

Npr., osnova od koje se polazi pri analiziranju ponašanja vozila u ovakvim situacijama, jeste geometrija i ponašanje sistema upravljanja i sistema vođenja točkova. Pored toga, jako je bitna kinematika pojedinih elemenata, tokom izvođenja određenih manevara. Dinamika vozila i njegovih podsistema, kao i njihovo ponašanje pri određenim pobudama, je, takođe, aspekt od krucijalnog značaja. Na kraju, „komunikacija“ između vozila i rukovaoca vozilom veoma je važna za sigurno održavanje kontrole nad vozilom.

Cilj rada jeste analiza uticajnih parametara na ponašanje vozila pri naglim promjenama pravca kretanja. Uz pomoć CAE simulacija na kompleksnom modelu i analitičkog proračuna za uprošćeni model dobijeni su određeni rezultati. Za tačno određene ulazne parametre dobijeni su određeni izlazni parametri, nakon čega je izvšena njihova analiza.

\footnotetext{
NAPOMENA:

Ovaj rad proistekao je iz master rada čiji mentor je bio dr Boris Stojić.
}

\section{TEORIJSKE OSNOVE BOČNE DINAMIKE VOZILA}

Ponašanje motornog vozila pri promjeni pravca kretanja je važna osobina vozila, za koju se najčešće koristi izraz upravljivost [1]. Upravljivost je izraz, kojim se označava odziv vozila na određenu pobudu, koju izaziva rukovalac vozila (vozača). Može se, takođe, reći da upravljivost opisuje vezu između vozača i vozila. Vozač i vozilo predstavljaju jedan ,zatvoren sistem“, u smislu da vozač daje komandu za način i pravac kretanja vozila, a takođe, isto tako, po potrebi, vrši korekciju zadanih komandi, kako bi postigao željeni način i pravac kretanja, ili željenu poziciju vozila, dok vozilo vraća povratnu informaciju u vidu odziva na zadatu komandu. U cilju određivanja ponašanja samog vozila, koristi se tzv. „otvorena petlja“ [1]. Otvorena petlja se koristi kako bi se iskazao odziv vozila na tačno određeni način aktiviranja vozačkih komandi.

\subsection{Stacionarno stanje}

Stacionarno stanje podrazumijeva kretanje vozila, pri kojem se parametri kretanja ne mijenjaju ili teže da se vrate na početnu vrijednost, ukoliko iz nekog razloga dođe do promjene. Stacionarno kretanje može biti translatorno, a može biti i kretanja po kružnici, odnosno obrtanje krutog tijela oko nepokretne ose, što odgovara kretanju vozila kroz krivinu određenog radijusa. Tokom ovakvog kretanja, vrijednosti ugla upravljača i brzine vozila su konstantne. Ono što se najčešće mjeri u otvorenoj petlji, jeste gradijent upravljivosti. Gradijent upravljivosti je veličina, koja određuje kako se potreban ugao zakretanja volana, za isti radiju krivine, mijenja sa promjenom bočnog ubrzanja vozila.

\subsubsection{Skretanje pri malim brzinama}

Tokom skretanja vozila pri malim brzinama (npr. pri parkiranju vozila), usljed veoma malih bočnih ubrzanja, bočne sile na pneumaticima, kao i vrijednosti povođenja točkova, su zanemarljivo male. Prema tome, u takvim uslovima kretanja, pneumatici se kotrljaju bez proklizavanja. Sve tačke vozila se kreću po koncentričnim kružnicama, čiji se radijusi i položaji centra ne mijenjaju u vremenu. Ovo predstavlja specijalan slučaj kretanja i analiza ovakvog kretanja služi za određivanje osnovnih karakteristika upravljivosti i stabilnosti.

Ako nema povođenja zadnjih točkova, centar zakretanja vozila mora ležati na pravoj, koja prolazi kroz zadnju osovinu. Poluprečnici skretanja oba prednja točka moraju da potiču iz istog centra zakretanja. Ukoliko se centri skretanja prednjih točkova ne bi poklapali, došlo bi do 
stvaranja neželjenih sila na prednjim pneumaticima tokom skretanja, do određenog proklizavanja i do dodatnog i ubzanog trošenja prednjih pneumatika.

Srednji ugao zakretanja prednjih točkova naziva se Akermanovim uglom [1] i izražava se kao:

$$
\delta=\frac{L}{R_{C}}
$$

gdje je:

$L$ - osovinsko rastojanje

$R_{C}$ - radijus krivine putanje centra mase vozila

Pojam „Akermanov ugao“ ili „Akermanova geometrija“ se koristi pri označavanju pravilne geometrije prednjih točkova pri skretanju. Tačne vrijednosti uglova zakretanja prednjih točkova zavise od osovinskog rastojanja i radijusa skretanja vozila

Radi lakše analize, uvodi se tzv. model vozila sa jednim tragom (,bicikl model“), prikazan na slici 1.

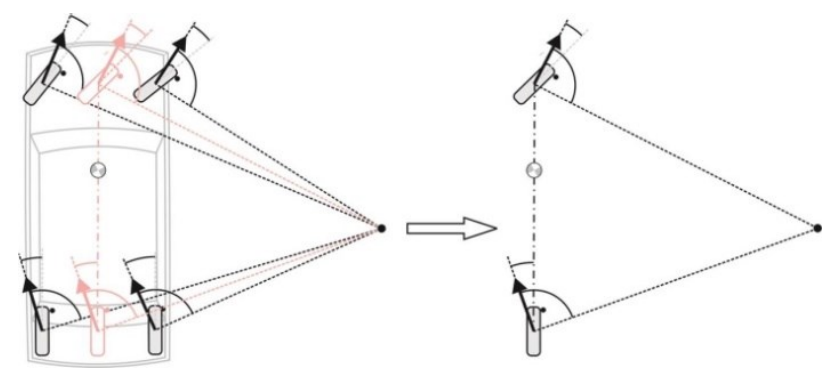

Slika 1. Model vozila sa jednim tragom [2]

Ovakav model je baziran na sljedećim uprošćenjima:

- Visina centra mase vozila u odnosu na podlogu je nula, odnosno centar mase leži na površini podloge. Ovim se eliminiše razlika između vrijednosti bočnih sila na spoljašnjim i unutrašnjim točkovima. Usljed toga, dva točka (desni i lijevi) se mogu svesti na jedan.

- Izrazi koji opisuju kretanje su linearizovani Linearizacija važi za uglove manje od $4^{\circ}$. Ova linearizacija takođe obuhvata i linearizaciju ponašanja pneumatika.

\subsubsection{Skretanje pri velikim brzinama}

Razlika u uslovima skretanja pri većim brzinama (kojima se vozilo kreće u saobraćaju) u odnosu na male brzine, jeste pojava izraženijeg bočnog ubrzanja pri većim brzinama. Da bi se bočne sile, koje djeluju na vozilo uravnotežile, na točkovima se razvijaju bočne sile suprotnog smjera. Takođe, u ovakvim uslovima, na svim točkovima će biti prisutna određena bočna povođenja.

Analizom geometrije sa slike 2, može se napisati izraz:

$$
\delta=\frac{L}{R_{C}}+\alpha_{f}-\alpha_{r}
$$

gdje je:

$\alpha_{f}$ - ugao povođenja prednjih točkova

$\alpha_{r}$ - ugao povođenja zadnjih točkova

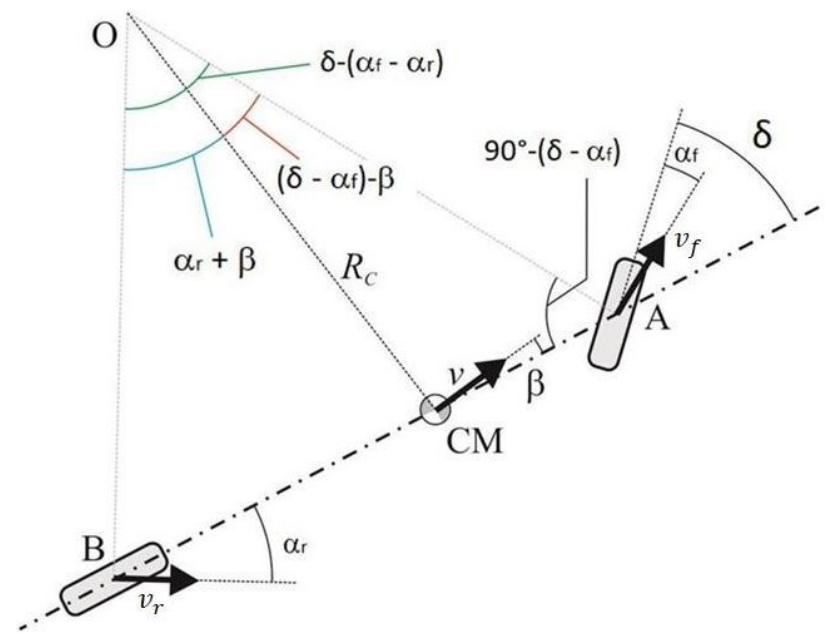

Slika 2. Analiza geometrije skretanja vozila pri većim brzinama [2]

Uz pomoć dinamičke analize i uvođenjem dodatnih pojednostavljenja [2]:

- uglovi povođenja točkova su mali

- $\quad$ radijus krivine putanje vozila je veliki

- radijus krivine je konstantan

- srednji ugao zakrenutosti prednjih točkova je konstantan,

dobija se izraz:

$$
\delta=\frac{L}{R_{C}}+\left(\frac{G_{f}}{C_{\alpha f}}-\frac{G_{r}}{C_{\alpha r}}\right) \cdot \frac{v^{2}}{g \cdot R_{C}}
$$

gdje je:

$C_{o r}$ - bočna krutost zadnjih $G_{f}$-stat. opt. prednje osov. pneumatika

$C_{\alpha f}$ - bočna krut. prednjih $v$ - transl. brzina vozila pneumatika

$G_{r}$ - stat. opt. zadnje osov. $\quad g$ - ubrzanje zemljine teže

Uzimanjem u obzir izraza za gradijent upravljivosti, dobija se:

$$
\delta=\frac{L}{R_{C}}+K \cdot \frac{a_{y}}{g}
$$

gdje je:

$K$ - gradijent upravljivosti

$a_{y}$ - bočno ubrzanje vozila

Od gradijenta upravljivosti zavise potrebni ulazni parametri za sistem upravljanja, pri savladavanju krivine određenog radijusa $\mathrm{R}$. Postoje tri različita karaktera upravljivosti, pomoću kojih se opisuje ponašanje vozila: neutralna upravljivost, podupravljivost i nadupravljivost.

\subsection{Nestacionarno stanje}

Nestacionarno kretanje vozila podrazumijeva kretanje u toku kojeg se mijenjaju vrijednosti parametara kretanja vozila (translatorna brzina kretanja, ugaona brzina, bočno ubrzanje...) 

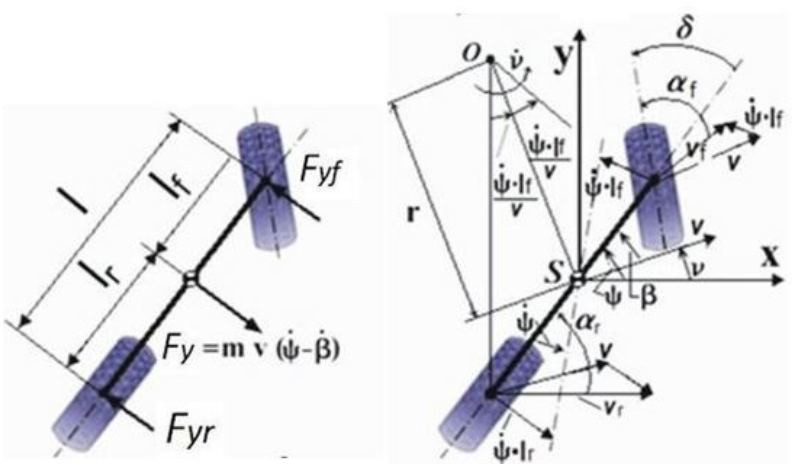

Slika 3. Analiza dinamike vozila tokom nestacionarnog kretanja [3]

Nakon dinamičke analize sa slike 3, uz pretpostavku da je brzina vozila konstantna, dobija se izraz:

$$
\begin{array}{r}
\ddot{\beta}+\left[\frac{C_{\alpha f}+C_{\alpha r}}{m \cdot v}+\frac{C_{\alpha f} \cdot l_{f}^{2}+C_{\alpha r} \cdot l_{r}^{2}}{\theta \cdot v}\right] \cdot \dot{\beta} \\
+\left[\frac{C_{\alpha r} \cdot l_{r}-C_{\alpha f} \cdot l_{f}}{\theta}+\frac{C_{\alpha f} \cdot C_{\alpha r} \cdot L^{2}}{\theta \cdot m \cdot v^{2}}\right] \cdot \beta= \\
{\left[-C_{\alpha f} \cdot \theta\right] \cdot \dot{\delta}+\left[\frac{C_{\alpha f} \cdot l_{f}}{\theta}-\frac{C_{\alpha f} \cdot C_{\alpha r} \cdot l_{r} \cdot L}{\theta \cdot m \cdot v^{2}}\right] \cdot \delta}
\end{array}
$$

gdje je:

$\beta$ - ugao plivanja c.m.

$\dot{\beta}-\operatorname{prvi}$ izvod $\beta$ po vrem.

$l_{r}$ - rast. c.m. od zadnje os.

$\ddot{\beta}$ - drugi izvod $\beta$ po vrem.

$m$ - masa vozila

$L$ - osovinsko rastojanje

$\theta$ - mom. inerc. oko z ose

$\delta$ - ugao zakrenutosti točk

$l_{f}$ - rast. c.m. od prednje os. $\quad \dot{\delta}$ - prvi izvod $\delta$ po vrem.

Dio prethodne jednačine, desno od znaka jednakosti, predstavlja homogeni dio jednačine i može se definisati kao smetnje $u$ toku kretanja, jer realne smetnje (neravnomijernost podloge i aerodinamičke smetnje) nisu uzete u obzir.

Lijevo od znaka jednakosti je homogeni dio jednačine. Može se primijetiti da ovaj dio ima isti oblik kao uobičajeni izraz za prigušenje vibracija:

$$
\ddot{\beta}+2 \cdot D \cdot \omega_{e} \cdot \dot{\beta}+\omega_{e}^{2} \cdot \beta=0
$$

$\mathrm{Na}$ osnovu izraza (4) i (5) moguće je odrediti sljedeće parametre prigušenja:

$>$ Neprigušena spostvena frekvencija:

$$
\omega_{e}=\sqrt{\frac{C_{\alpha r} \cdot l_{r}-C_{\alpha f} \cdot l_{f}}{\theta}+\frac{C_{\alpha f} \cdot C_{\alpha r} \cdot L^{2}}{\theta \cdot m \cdot v^{2}}}
$$

Koeficijent prigušenja:

$$
D=\frac{1}{2 \cdot \omega_{e}} \cdot\left[\frac{C_{\alpha f}+C_{\alpha r}}{m \cdot v}+\frac{C_{\alpha f} \cdot l_{f}^{2}+C_{\alpha r} \cdot l_{r}^{2}}{\theta \cdot v}\right]
$$

$>$ Prigušena sopstvena frekvencija:

$$
\omega_{e d}=\omega_{e} \cdot \sqrt{1-D^{2}}
$$

\section{OPIS SOFTVERA ZA SIMULACIJU I MODELIRANJE „ADAMS CAR“}

\subsection{Pristup dinamici uz pomoć softvera „Adams“}

Ovo je softver koji pomaže pri proučavanju dinamike pokretnih elemenata i analiziranju uticaja i rasporeda opterećenja i sila, koji djeluju na mehaničke sisteme. Zajedno sa širokim spektrom mogućih analiza optimizovan je za rješavanje najkompleksnijih dinamičkih problema.

Kao najpoznatiji softver za proučavanje dinamike mehaničkih sistema, Adams doprinosi poboljšavanju efikasnosti inženjera i smanjuje troškove dobijanja konačnog proizvoda, omogućavajući njegovu raniju validaciju kao dinamički uravnoteženog sistema.

\subsection{Opis dopunskog modula „Adams Car“}

Adams Car je dio softvera Adams, koji služi modeliranju i ispitivanju vozila. Glavna svrha korištenja ovog softvera $u$ automobilskoj industriji, jeste simulacija ponašanja modela vozila, kao i njegovih podsistema pojedinačno. Ovi modeli se npr. često koriste za simulaciju ponašanja vozila pri dejstvu nelinearnih vibracija velikih amplituda, kao što su vibracije koje potiču od pogonskog agregata ili transmisije.

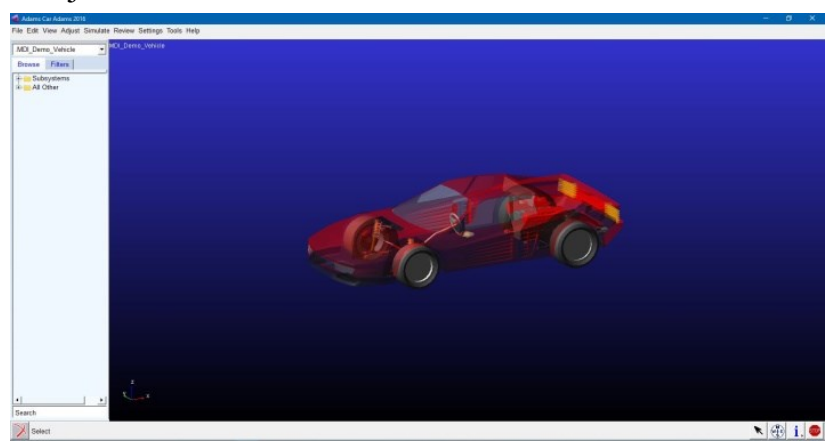

Slika 4. Model vozila u softverskom okruženju

\subsubsection{Manevri u otvorenoj petlji}

Sa aspekta kontrole izlaznih parametara nekog sistema, postoji sistem sa kontrolom $u$ otvorenoj $i$ sistem sa kontrolom u zatvorenoj petlji. Suštinska razlika između ovih sistema je u tome što sistem sa otvorenom petljom ne daje povratnu informaciju na ulaz u sistem.

Adams Car, pored ostalog, nudi mogućnost simulacije različitih manevara u otvorenoj petlji: Drift, Fish-Hook, Impulse steer, Ramp steer, Single Lane-Change, Step steer, Swept-Sine steer.

Manevar promjene ugla upravljača po odskočnoj funkciji (Step steer) se koristi za analizu izlaznih parametara $\mathrm{u}$ vremenskom domenu i korišten je u simulaciji predstavljenoj u glavnom dijelu rada.

\section{ANALIZA PRORAČUNSKIH I SIMULACIJSKIH REZULTATA}

\subsection{Proračun parametara tranzijentnog odziva vozila na bazi pojednostavljenog modela}

U ovom potpoglavlju su analitičkim putem određeni parametri tranzijentnog odziva vozila, usljed impulsne pobude. Ova pobuda se manifestuje kratkotrajnim dejstvom bočne sile na vozilo, koje izaziva kratkotrajni izlazak vozila iz stacionarnog stanja. 
Korištenjem parametara vozila, usvojenim iz baze podataka Adams Car-a, i izraza (6), (7) i (8), za tri različite brzine dobijeni su sljedeći rezultati:

Pri 40 km/h:

$\omega_{e}=29.49 \mathrm{~Hz}, D=1.03, \omega_{e d}=29.49 \cdot \sqrt{-0.0609} \mathrm{~Hz}$

Pri $80 \mathrm{~km} / \mathrm{h}$ :

$\omega_{e}=16.16 \mathrm{~Hz}, D=0.94, \omega_{e d}=0.33 \mathrm{~Hz}$

Pri $120 \mathrm{~km} / \mathrm{h}$ :

$\omega_{e}=12.18 \mathrm{~Hz}, D=0.83, \omega_{e d}=0.55 \mathrm{~Hz}$

Pri brzini od $40 \mathrm{~km} / \mathrm{h}$, odziv vozila je nadkritično prigušen. Pri brzinama od 80 i $120 \mathrm{~km} / \mathrm{h}$, i pored smanjenja koeficijenta prigušenja, vrijednost frekvencije sopstvenih prigušenih oscilacija je zanemarljivo mala, tako da se i ove vrijednosti mogu zanemariti i aproksimirati kao nadkritično prigušene.

\subsection{Manevar promjene ugla upravljača po odskočnoj funkciji}

U ovom dijelu rada predstavljena je analiza rezultata, dobijenih simuliranjem manevra promjene ugla upravljača po odskočnoj funkciji, u softverskom okruženju Adams Car. Kao model simulacije korišten je kompleksan model vozila. Osnovni parametri vozila su isti kao kod pojednostavljenog modela, ali je sam model mnogo kompleksniji, a time i mnogo realniji.

Simuliranje je izvedeno u tri iteracije. Brzina je, ponovo, parametar koji ima različite vrijednosti u sve tri iteracije (40, 80 i $120 \mathrm{~km} / \mathrm{h})$.

\subsubsection{Bočno ubrzanje}

U ovom dijelu su prikazane karakteristike bočnog ubrzanja tokom tri navedene iteracije.

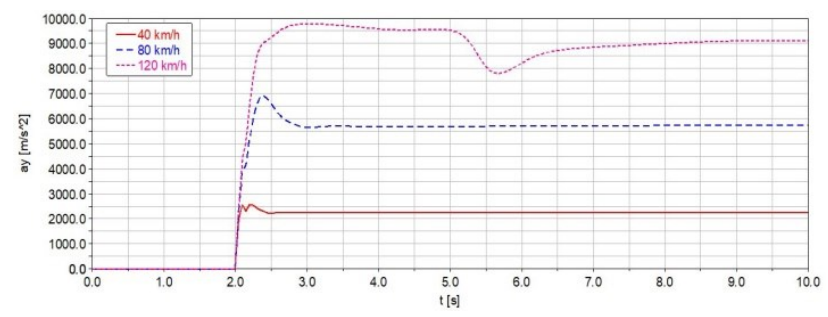

Slika 5. Karakteristike bočnog ubrzanja

Vrijednost bočnog ubrzanja raste sa porastom brzine kretanja vozila, što je vidljivo na slici 5. Kao što može da se vidi, manevar počinje u drugoj sekundi simulacije i na početku manevra se dešava nagli skok vrijednosti.

U prve dvije iteracije (40 i $80 \mathrm{~km} / \mathrm{h}$ ), vrijednost bočnog ubrzanja blago osciluje i zatim se ustaljuje na nekoj konstantnoj vrijednosti. Maksimum u prvo iteraciji je $\approx 2.6 \mathrm{~m} / \mathrm{s}^{2}$, dok se u drugoj penje na vrijednost od $\approx 9.8$ $\mathrm{m} / \mathrm{s}^{2}$. Ustaljenje u prvoj iteraciji se dešava pri vrijednosti od $\approx 2.25 \mathrm{~m} / \mathrm{s}^{2}$, a u drugoj pri $\approx 5.75 \mathrm{~m} / \mathrm{s}^{2}$.

Treća iteracija (pri $120 \mathrm{~km} / \mathrm{h}$ ) daje nepravilnu karakteristiku, koja govori da bi realno izvođenje manevra, pri ovoj brzini, bio prilično težak zadatak za rukovaoca vozilom sa prosječnim sposobnostima.

\subsubsection{Ugaona brzina}

$\mathrm{U}$ ovom dijelu su date i analizirane ugaone brzine, kao izlazni parametri simulacija.

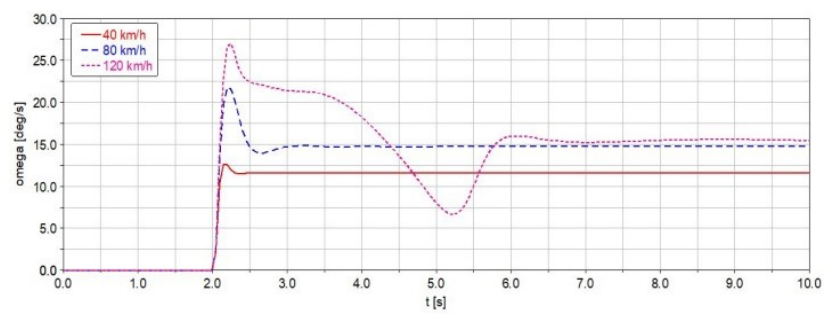

Slika 6. Karakteristike ugaonih brzina

Na slici 6 predstavljene su karakteristike ugaone brzine, dobijene $u$ tri navedene iteracije.

Karakter promjene vrijednosti ovog izlaznog parametra je sličan promjeni bočnog ubrzanja. U prve dvije iteracija, vrijednost ugaone brzine skače na neki maksimum, a zatim se uz blage oscilacije ustaljuje na konstantnu vrijednost. Maksimum vrijednosti u prvoj iteraciji je 12.3 $\%$ s, a u drugoj $22 \%$ s. Ustaljene vrijednosti ugaonih brzina u prvoj i drugoj iteraciji su $11.8 \%$ s i $15 \%$ s, respektivno.

I u ovom slučaju je vidljiv porast vrijednosti analiziranog izlaznog parametra sa porastom brzine kretanja vozila, što je u skladu sa teorisjkim očekivanjima.

Takođe, i kod ovog parametra, karakteristika pri brzini od $120 \mathrm{~km} / \mathrm{h}$, ima nepravilan oblik, što potvrđuje pretpostavku o mogućnosti gubitka kontrole nad vozilom, u realnim uslovima izvođenja manevra.

\section{ZAKLJUČAK}

Kod analitički dobijenih rješenja, model je pokazao nadkritična prigušenja. Takva rješenja nisu validna $u$ ocjeni ponašanja vozila. Zaključak je da je model previše pojednostavljen.

Model korišten u softverskoj simulaciji je visoko kompleksan, a time i prilično vjeran realnom modelu. U ovom slučaju, rezultati imaju oscilatorni karakter, što opravdava teorijska očekivanja.

\section{LITERATURA}

[1] T. D. Gillespie, „Fundamentals of Vehicle Dynamics”, 1992.

[2] B. Stojić, „Predavanja iz TKDV“, FTN Novi Sad 2018., mehanizacija.uns.ac.rs (pristupljeno u martu 2019.)

[3] B. Heissig, M. Ersoy, „Chassis Handbook“ 2011.

\section{Kratka biografija:}

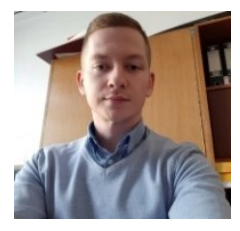

Dalibor Pelagić rođen je u Brčkom $(\mathrm{BiH})$ 1994. god. Diplomski rad na Fakultetu tehničkih nauka iz oblasti Mašinstva -

Mehanizacija i konstrukciono mašinstvo odbranio je 2017.god., nakon čega je upisao master studije. 